\title{
Promoting Reflection in Asynchronous Virtual Learning Spaces: Tertiary Distance Tutors' Conceptions
}
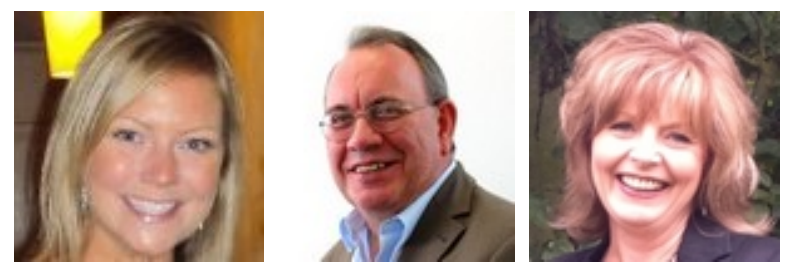

Bethany Alden Rivers ${ }^{1}$, John T. E. Richardson 2 , and Linda Price ${ }^{2}$ ${ }^{1}$ The University of Northampton, UK, ${ }^{2}$ The Open University, UK

\section{Abstract}

Increasingly, universities are embedding reflective activities into the curriculum. With the growth in online tertiary education, how effectively is reflection being promoted or used in online learning spaces? Based on the notion that teachers' beliefs will influence their approaches to teaching, this research sought to understand how a group of distance tutors at the UK Open University conceptualised reflection. It was hoped that these findings would illuminate their approaches to promoting reflection as part of their online pedagogies. Phenomenographic analysis indicated that these tutors conceptualised reflection in four qualitatively different ways. Furthermore, the data suggested that these educators held a combination of two conceptions: one that understood the origin of being reflective and one that understood the purpose of reflection. Analysis of structural aspects of these conceptions offered insight into tutors' own perspectives for what is needed to make online learning environments fertile territory for reflective learning.

Keywords: Distance learning; online learning and teaching; reflective learning; asynchronous forums 


\section{Introduction}

Frameworks for reflective learning have developed over the last century as researchers and practitioners have sought to enhance the learning experience. Kolb's (1984) experiential learning model, Boud, Keogh, and Walker's (1985) model of reflection, Brookfield's (1987) model for critical thinking, and Gibbs' (1988) reflective cycle are examples of frameworks that explain the role of reflection in learning. All of these learning models are underpinned by Dewey's (1910) notion that reflection is the catalyst for moving between theory and practice. Fundamentally, they all share similar stages of "retrospection", "self-evaluation" and "reorientation" (Quinn, 2005, p. 81). Reflection has been proposed as a stage in a developmental hierarchy (van Manen, 1977; Schön, 1987). Others have located reflective activity in the upper levels of social development models (Perry, 1970; Butler, 1996). Reflection, it seems, plays a very important role in one's development.

Increasingly, universities are embedding reflective activities into the curriculum, especially in courses that lead to professional qualifications (Ross, 2011). Higher education institutions champion the idea of fostering reflective practitioners, often viewing reflective practice as a key learning outcome (Barnett, 1992). Theories such as Schön's (1983, 1987) "reflection-in-action" and "reflection-on-action" underline contemporary professional development (Eby, 2000).

Reflection is seen as an important theme in personal development planning and personal development plans are seen as an important link between employability, enterprise and employer engagement (QAA, 2001; Watts \& Butcher, 2008). There is a wealth of literature that suggests reflection is the key to being a "transformational" learner and an agent of one's own learning (e.g., Mezirow, 1990). Central to this, some literature hints that reflection can promote deeper learning (Clare, 2007; Davys \& Beddoe, 2009).

Facilitating reflective learning requires teachers to engage in a reflective relationship with students through intentional reflective dialogue (Brockbank \& MoGill, 1998). Indeed, the notion of "connected teaching" is based on the importance of a shared dialogue between teachers and students to "think and talk together" (Belenky et al., 1986, p. 219). Features of the learning environment, the institution's management structure and the quality of the learning activities all play a role in creating a learning space that is conducive to reflective learning (Moon, 1999). As a growing number of universities explore opportunities for online and distance education, teachers will need to develop their own online and distance pedagogies (McDonald et al., 2012). Working with cohorts in an online environment can be opportunity to engage in an ongoing construction of knowledge (Tisdell et al., 2004). And, as reflection is such a powerful ingredient for learning, it needs to be effectively promoted in online learning contexts (J ohnson \&Aragon, 2003). 


\section{The Problem}

Asynchronous online conferencing is widely utilised as a teaching and learning tool in distance learning university courses (Andresen, 2009). However, studies have suggested that achieving an active level of participation (Einon, 2010) and an effective degree of communication (Price et al., 2007) in these online contexts is challenging for distance tutors. Despite the potential for asynchronous discussion to "capture learning in action" (McDonald et al., 2012, p. 32), it is difficult for teachers to structure asynchronous online discussions that engage students in meaningful discourse (Gilbert \& Dabbagh, 2005). Without opportunities to develop reflective relationships and to engage in intentional reflective dialogue, how effectively is reflection being facilitated in online learning spaces?

Despite the apparent advantages for teachers to promote reflective skills, it is unreasonable to assume that all teachers will have the same approaches to and understandings of reflection. Studies have shown that teachers' approaches to teaching are strongly influenced by their own beliefs (Kember, 1997) and that teachers' approaches to teaching can influence learners' approaches to studying (Trigwell, Prosser, \& Waterhouse, 1999). This study explored distance tutors' beliefs about reflection in order to illuminate their approaches to encouraging reflection in online spaces.

\section{Theoretical Background}

Early writings on teachers' orientations to reflection focus on the pursuit of effective teaching. Van Manen (1977) drew on Habermas's (1974) ideas regarding the movement of theory to practice in terms of pedagogical effectiveness. He reasoned that if Habermas was able to construct links between theory and practice on the basis of "cognitive interest", then it should be possible to apply these links to the activity of "making students learn" (p. 225). Van Manen postulated that there were three hierarchical levels of pedagogical reflectivity: 1) as a "means to an end", 2) as a "process of analysing and clarifying individual and cultural experiences", and 3) as a "worthwhile educational end...on the basis of justice, equality and freedom" (pp. 226-227). Van Manen proposed that teaching required the highest level of reflectivity (Level 3) in order to impart the emancipatory benefits of knowledge.

Building on van Manen's levels of reflectivity, Grimmett, Mackinnon, Erickson, and Riecken (1990) summarised three perspectives on reflection in teacher education. They referred to the basic orientation to reflection as "technical", meaning that reflection is a necessary tool in mediating action. The next, higher, perspective on reflection is called "deliberative" and involves thinking between "competing views of teaching". The third, and highest, orientation to reflective practice is termed "dialectical" and works to "apprehend and transform" (p. 35). Two additional orientations to reflection were later proposed by Wellington and Austin (1996). They took the view that a more basic level was required, one where reflection did not really occur. This orientation, referred to as 
"immediate", focused more on "pleasant survival". Additionally, Wellington and Austin proposed that an orientation beyond van Manen's and Grimmett et al.'s highest level of reflective practice should exist, one that centred on "universal personal liberation". This orientation was labelled "transpersonal” (pp. 309-311).

This framework provides a clear description of five ways that teachers orientate to reflective work. However, Wellington and Austin recognised that the reliance on selfreported data in constructing the model meant that it may neglect tacitly held beliefs ( $\mathrm{p}$. 313). Furthermore, although van Manen's original theory described these orientations as hierarchical, the flowchart depicted in Wellington and Austin's work does not appear to provide space for practitioners to move between reflective orientations. This is conflicting with van Manen's (1977) notion that practitioners' reflective orientations can change as they experience "a shift from one reality to another" (p. 212).

Ruch $(2000,2002)$ argued that van Manen's original model of three levels of reflectivity failed to consider the "unconscious and conscious processes at work in inter-personal encounters" and suggested that a fourth level of reflectivity should be added. Ruch termed this level "process reflection".

The opportunity to reflect, to think about and feel, as well as act on, the relationship dynamics and associated thoughts and feelings, enables professionals (educators, practitioners, researchers) to gain insight into the experiences of those with whom they work and their own responses to situations. (2002, p. 205)

Clearly, teachers approach reflection in different ways. A teacher's approach to promoting reflection in online spaces may be influenced by their conceptions of elearning. Kirkwood and Price (2005) claimed that the efficacy of online teaching relies heavily on the relationship between the teacher and the technology. In a later study, Kirkwood and Price (2012) claimed that most of the research into teaching and learning with the use of online tools has neglected the conceptions that instructors and curriculum designers hold of these technologies. They argued that conceptions of these phenomena will affect the approach used in online teaching and that these ideas and approaches will be influenced by the technological context. These authors concluded that, in illuminating these areas, better decisions can be made regarding course design and delivery.

Stein et al. (2011) carried out a phenomenographic study to "identify the variety of conceptions of e-learning and professional development for e-learning by teaching and teaching-support staff" (p. 150). The project involved a cross section of higher education teachers and staff members across New Zealand. Findings from this research showed there were five conceptions of e-learning among tertiary educators: 1) e-learning as tools, equipment, hardware and software; 2) as a means through which learning interaction is facilitated; 3) as learning; 4) as a means through which to reduce distance 
between and among teachers, students, and the course materials; and 5) as a collaborative enterprise (pp. 150-153).

While studies such as Kirkwood and Price's and Stein et al.'s work toward a better understanding of teachers' conceptions of e-learning, there is a dearth of knowledge related to the ways in which teachers in higher education conceptualise reflection.

\section{Design and Method}

The design followed a phenomenographic approach to investigate the qualitatively different ways in which distance tutors understood the phenomenon of reflection (Marton, 1986). Phenomenography seeks to gain a "second-order perspective" (Marton, 1981, p. 177), whereby the goal is to describe "an aspect of the world as it appears to the individual" (Marton, 1986, p. 33). Open-ended email questionnaires and follow-up telephone interviews were used to collect data from the participants. The questionnaire included two demographic questions and 13 open-ended questions. The interviews lasted between 10-20 minutes and involved approximately 12 open-ended questions. Some of the questions were adapted from Stein et al.'s (2011) study and the order of questioning (e.g., “What do you mean by 'reflection'?” posed at the end of the survey) echoed Säljö’s (1979) approach to interviewing for his study on conceptions of learning. Gender-specific pseudonyms are provided in this paper to maintain the anonymity of the participants.

\section{Participants}

This study used data collected from nine distance tutors on a business management module, B121: Managing in the Workplace, at the UK Open University. Participants included two female and seven male tutors, who responded to a request to take part in a practice-based study. This particular module is underpinned by Kolb and Fry's (1975) experiential learning cycle and the assessments for this module include aspects of personal development and reflection. Furthermore, this module is supported primarily by an asynchronous online conference. All nine participants took part in the first phase of the research (the open-ended email questionnaire) and of these participants, eight were available for follow-up interviews. (See Appendices A and B for the questionnaire and interview protocol.) All of the participants were familiar and comfortable with the chosen data collection methods (i.e., email and telephone) and they were able to clearly articulate their own ideas relating to reflection.

\section{Analytic Methods}

Analysis of phenomenographic data involves identifying a small set of "qualitatively distinct descriptive categories", or conceptions (Booth, 1997, p. 138). The process is summarised by Marton (1994) as follows: 
The interviews are transcribed verbatim and the analysis is carried out in an iterative manner on those transcripts. Distinctly different ways of experiencing the phenomenon discussed in the interview are the units of analysis and not the single individuals. The categories of description corresponding to those differing understandings and the logical relations that can be established between them constitute the main results of phenomenographic study. (p. 4424)

Broadly speaking, the analysis of these data followed Marton's description. However, the analysis studied two different strands based on Marton and Pong's (2005) explanation that there are two aspects to every conception. First there is the "referential aspect", or what would be typically considered as the meaning of an object. Second, there is a "structural aspect", which involves the different features of the conception or, in this case, the participants' perspectives within the conception (p. 336).

These data were analysed in several phases. Initially, the transcripts were scanned to identify key themes. A list of these themes was compiled and then grouped into related categories. Through an iterative process of regrouping and refining, a set of conceptions-or, the referential aspect-emerged. Then, the evidence to support the existence of each conception was investigated more closely. This helped to understand the structural aspect of each category.

\section{Results}

The analysis of these data yielded four different ways that these tutors conceptualised reflection: 1) as a trait, 2) as learning, 3) as an activity, and 4) as a skill. An interesting feature of these tutors' conceptions of reflection was that all of the participants seemed to hold a combination of two conceptions. Four of the tutors thought of reflection as both a skill and an activity. Three of the participants considered reflection as both a skill and as learning. One tutor conceptualised reflection as a personality trait and as learning. The majority notion that reflection is a skill implies that these tutors believed reflection can be taught or developed. The evidence suggests that the tutors thought about this aspect of reflection in terms of requiring time and practice.

Interview response: Mary
Yeah, I think I try hard to be...yeah, I think I'm reflective. I do think I work hard at that aspect. 
Interview I'm sure we'd be more reflective practitioners if we response: $\quad$ had more time to reflect.

Luis

A few of the participants were able to talk about reflection in terms of their own experiences as a learner on a professional development course.

\begin{tabular}{|c|c|}
\hline $\begin{array}{l}\text { Survey } \\
\text { response: Luis }\end{array}$ & $\begin{array}{l}\text { I recently completed a piece of work that } \\
\text { required use of reflection to help consider } \\
\text { more abstract theories. }\end{array}$ \\
\hline $\begin{array}{l}\text { Survey } \\
\text { response: } \\
\text { Mohammed }\end{array}$ & $\begin{array}{l}\text { When I was doing my MBA, I put some } \\
\text { things into my blog. It was useful to see just } \\
\text { how I was thinking back then. }\end{array}$ \\
\hline $\begin{array}{l}\text { Survey } \\
\text { response: } \\
\text { J ohn }\end{array}$ & $\begin{array}{l}\text { It wasn't until I did my PGCE that I realised } \\
\text { how frightful reflection is. In my previous } \\
\text { jobs, reflection wasn't particularly } \\
\text { important. But I've changed tack now and } \\
\text { I've realised how important it is. }\end{array}$ \\
\hline
\end{tabular}

When discussing reflection as an activity, the teachers used action words to explain their ideas: "stepping back...", "recalling experiences", "constructing thoughts", and "interrogating our thoughts". Tutors who held conceptions of reflection as learning were able to link these activities to developmental outcomes.

$\begin{array}{ll}\begin{array}{l}\text { Survey } \\ \text { response: } \\ \text { Mary }\end{array} & \begin{array}{l}\text { Learning-making the unconscious } \\ \text { conscious...to help us decide how we will } \\ \text { approach a current situation or problem. }\end{array} \\ \begin{array}{l}\text { Survey } \\ \text { response: }\end{array} & \begin{array}{l}\text { Thinking about events which have passed } \\ \text { and pausing to consider whether there is } \\ \text { any learning to be had from these. }\end{array} \\ \begin{array}{l}\text { Survey } \\ \text { response: }\end{array} & \begin{array}{l}\text { Reviewing action and performance so that } \\ \text { Malcolm }\end{array} \\ \end{array}$

Despite conceptualising reflection as an important element of higher learning, these teachers remarked that other factors constrained their ability to promote reflective learning in the asynchronous forum (referred to as the tutor group forum or TGF). The main factor, according to the participants, seemed to be low rates of participation on the TGF. 
Researcher: How important is the TGF in your role as a distance tutor?

J ohn: As far as [this module] is concerned?

Researcher: Yes.

J ohn: I hate it. [laughing]

Researcher: Why?

John: Because I'm speaking into a void. They don't answer me. They don't talk to me. I hate it. There must be another way.

There was also some indication that the module design was a constraining factor in operationalising reflective learning.

Researcher: Okay. And, how important is the TGF in your role as a distance tutor?

Sarah: Well, on this course, not as important as it might be really. But I'd prefer it to be much more important.

Researcher: Okay, what could the University or the module team do to make the TGF a more effective tool for you?

Sarah: Um, I think the critical issue is devising activities which are both engaging and also really kind of force students to engage with the TGF.

There was a suggestion that reflective activities could be designed and provided by the module team to be used on the forums.

Interview There are no centralised activities, you know, response: that come from the module team. That could be Mohammed helpful.

Many of the tutors remarked that their online pedagogies were affected by this module's assessment strategy. Participation in the online forum is not required on this particular course and, if it were, teachers feel they would have more opportunities to promote reflection on the TGF. 
Interview
response:
John

Interview

response:

Malcolm ...as soon as they find out there's no marks allocated, they don't bother. Then I say to them: 'please participate'. What's the point? They don't get any marks given to them.

And because it's not assessed it's very difficult to keep the enthusiasm with people working on the TGF and if I'm being totally honest, my enthusiasm in trying to keep people going on it low. Their argument is 'well I'll do it but only if it's of benefit'.

The other big factor was time, both personal time available to "teach" and the temporal dimension of asynchronous learning technologies. The belief that these educators held that reflection takes time seemed to influence the way they thought about promoting reflection on the TGF.

Interview I think that's the problem, none of us really have response: the time to reflect with work so its there in [the Malcolm course] and it will come out in the assignment, rather than the TGF I think.

Also, the timeliness of using the forum for teaching and learning was laughable by some of the teachers.

$\begin{array}{ll}\text { Interview } & \text { I know it's asynchronous but it's very } \\ \text { response: } & \text { asynchronous. [okay...laughing] umm, yeah, } \\ \text { Malcolm } & \text { rather than everybody going in there every } \\ & \text { three days and then in three days everyone's } \\ & \text { got an answer to their questions, or have had } \\ & \text { an opportunity to participate, and then } \\ & \text { another three weeks and they aren't there at } \\ & \text { all. }\end{array}$

\section{Discussion}

Barnett (1992) described the institutional space between a student's entry into and exit from higher education as the "black box" (p. 99). This black box holds "an array of invisibles" that, among other things, includes the educational backgrounds, values, feelings and beliefs of its teachers. This study aimed to learn more about teachers' beliefs about reflection in the hope that doing so would shed light on how they promoted reflection in online learning contexts. 
The findings of this study indicated that these distance teachers each held a pair of conceptions related to reflection. One conception dealt with the origin of the phenomenon (whether it was an innate feature or a learned skill) and the other conception in the pair addressed the purpose of reflection (whether it was a discrete activity or whether it was developmental). The dualist nature of this phenomenon may reflect the way the data was collected (i.e., the questionnaire and interview questions). It may also be an indication that the participants were considering the questions from different stances.

The notion of stance is an important consideration in the learning context. Salmon (1989) explained that the stance a teacher takes is representative of his or her knowledge and understanding. Brockbank and McGill (2007) suggested that even a teacher's best efforts at hiding their own struggles at engaging with or being enthusiastic about a particular aspect of learning will not trick anyone in the longer term. Resentment of particular approaches to teaching will influence the learning situation. While the findings of this study seemed largely positive regarding teachers' conceptions of reflection, their comments about promoting reflection in the forums were often negative. When relating the contents of the black box to the student experience, it seems pertinent for teachers to be aware of their personal stance toward certain approaches to learning, particularly when trying to develop a reflective relationship with their students.

Norton et al. (2005) investigated teachers' beliefs of "knowledge transmission" and "learning facilitation", while simultaneously asking their participants to rank their approach to teaching (p. 542). Norton et al. differentiated between teachers' intentions (intended approaches) and teachers' conceptions (beliefs) by arguing that "teaching intentions thus reflect a compromise between teachers' conceptions of teaching and their academic and social contexts" (p. 537). In the case of this present study, the teachers' relatively positive intentions for promoting reflection on the forums were affected by both their institutional and social contexts as well as their underlying beliefs about the phenomena. Teachers in this study noted that low participation rates in the forums, the design of the module, the lack of pre-fabricated reflective learning activities, too little time to facilitate reflection, and the asynchronous gap were constraining factors in promoting reflective learning in the forums.

While there is literature to suggest that asynchronous forums typically suffer from low participation rates, it seems plausible that by addressing some of these other perceived constraints, students and staff may come to understand these forums as valuable learning tools. Perhaps the use of protocols for online discussions, as promoted by Gilbert and Dabbagh (2005) and McDonald et al. (2012), would provide structured activities for fostering reflective online discourse. The use of these protocols may also assuage teachers' concerns about not having enough time to promote reflection in the forums. Despite these teachers' concerns that the asynchronous nature of the forums does not provide scope for reflection, Hamilton and Cherniavsky (2006) explained that an asynchronous discussion thread is a record of a student's deliberate and focused 
understanding of a particular topic. Such a space offers great potential for learning and understanding, which, according to learning theory, necessitates reflection. Perhaps universities need to 'shout louder' about the potential of asynchronous fora to facilitate reflective learning.

Further research regarding teachers' conceptions of and approaches to reflection in online spaces could yield more salient and generalisable findings for institutions considering or developing e-learning technologies. The gender composition of this sample may have influenced the findings. Similar studies with equal number of male and female participants and/or comparison studies of wholly male and wholly female samples may yield interesting insights. Findings related to the dual-conceptions of reflection among practitioners offer a foundation for further studies on personal stance and the institutional and social contexts of practitioners are important to consider, both as catalysts and as constraints.

\section{Acknowledgements}

We are grateful to the B121 module team at the UK Open University for endorsing this study. 


\section{References}

Andresen, M. A. (2009). Asynchronous discussion forums : Success factors, outcomes, assessments and limitations. Educational Technology \& Society, 12, 1, 249-247.

Barnett, R. (1992). Improving higher education. Buckingham: SRHE/ Open University Press.

Belenky, M. F., Clinchy, B. M., Goldberger, N. R., \&Tarule, J . M. (1986). Women's ways of knowing: The development of self, voice, and mind. New York : Basic Books.

Booth, S. (1997). On phenomenography, learning and teaching. Higher Education Research \& Development, 16(2), 135-158.

Boud, D., Keogh, R., \&Walker, D. (1985). Promoting reflection in learning: A model. In D. Boud, R. Keogh, \&D. Walker (Eds), Reflection: Turning experience into learning. London: Kogan Page.

Brockbank, A., \& McGill, I. (2007). Facilitating reflective learning in higher education (2nd ed.). Buckingham: Open University Press.

Brookfield, S. D. (1987). Developing critical thinkers. Milton Keynes: Open University Press.

Butler, J . (1996). Professional development: Practice as text, reflection as process, and self as locus. Australian J ournal of Education, 40(3), 265-283.

Clare, B. (2007). Promoting deep learning: A teaching, learning and assessment endeavour. Social Work Education, 26(5), 433-446.

Davys, A. M., \& Beddoe, L. (2009). The reflective learning model: supervision of social work students. Social Work Education. Retrieved from http:// dx.doi.org/ 10.1080/02615470902748662

Dewey, J . (1910). How we think. Lexington, D. C.: Heath.

Eby, M. A. (2000). Understanding professional development. In A. Brechin, H. Brown, \&M. A. Eby (Eds.), Critical practice in health and social care. London : Sage.

Einon, G. (2010). Managing computer-supported collaboration. In H. Donelan, K. Kear, \& M. Ramage (Eds), Online communication and collaboration: A reader. Abingdon: Routledge.

Gibbs, G. (1988). Learning by doing: A guide to teaching and learning methods. Oxford: Further Education Unit, Oxford Polytechnic. 
Gilbert, P. K., \&Dabbagh, N. (2005). How to structure online discussions for meaningful discourse: A case study. British J ournal of Educational Technology, 36(1), 5-18.

Grimmett, P. P., Mackinnon, A. M., Erickson, G. L., \& Riecken, T. J . (1990). Reflective practice in teacher education. In R. T. Clift, Houston, \& M. C. Pugach, (Eds), Encouraging reflective practice in education. New York: Teachers' College Press.

Habermas, J . (1974). Theory and practice. Boston: Beacon Press.

Hamilton, E., \& Cherniavsky, J . (2006). Issues in synchronous versus asynchronous elearning platforms. In H. F. O’Neil \& R. S. Perez (Eds), Web-based learning: Theory, research and practice. Mahway: Erlbaum.

J ohnson, S., \&Aragon, S. (2003). An instructional strategy framework for online learning environments. New Directions for Adult and Continuing Education, 100, 31-43.

Kember, D. (1997). A reconceptualisation of the research into university academics' conceptions of teaching. Learning and Instruction, 7(3), 255-275.

Kirkwood, A., \& Price, L. (2012). The influence upon design of differing conceptions of teaching and learning with technology. In A. D. Olofsson \& O. Lindberg (Eds), Informed design of educational technologies in higher education: Enhanced learning and teaching. Pennsylvania, USA: IGI Global.

Kirkwood, A. T., \& Price, L. (2005). Learners and learning in the twenty-first century: What do we know about students' attitudes towards and experiences of information and communication technologies that will help us design courses? Studies in Higher Education, 30(3) 257- 274.

Kolb, D. (1984). Experiential learning as the source of learning and development. New J ersey: Prentice Hall.

Kolb, D.A., \& Fry, R. (1975). Towards an applied theory of experiential learning. In C. L. Cooper (Ed), Theories of group processes. London: J ohn Wiley.

Marton, F. (1986). Phenomenography—a research approach to investigating different understandings of reality. J ournal of Thought, 21(3), 28-49.

Marton, F. (1994). Phenomenography. In T. Husen \& T. N. Postlethwaite (Eds), The international encyclopaedia of education, 8, 4424-4429. Oxford: Pergamon.

Marton, F., \& Pong, W.Y. (2005). On the unit of description in phenomenography. Higher Education Research \&Development, 24(4), 335-348. 
Marton, F., \& Säljö, R. (1976). On qualitative differences in learning, I. Outcome and process. British J ournal of Educational Psychology, 46, 4-11.

McDonald, J .P., Mannheimer Zydney, J., Dichter, A., \& McDonald, E.C. (2012). Going online with protocols: New tools for teaching \&learning. New York: The Teachers College Press, Columbia University.

Mezirow, J . (1990). Fostering critical reflection in adulthood. San Francisco: J osseyBass.

Moon, J . (1999). Reflection in learning and professional development. London: Kogan Page.

Norton, L., Richardson, J . T. E., Hartley, J ., Newstead, S., \& Mayes, J . (2005). Teachers' beliefs and intentions concerning teaching in higher education. Higher Education, 50, 537-571.

Perry, W. G. (1970). Forms of intellectual and ethical development in the collegeyears: A scheme. New York: Holt, Rinehart and Winston, Inc.

Price, L., Richardson, J .T.E., \&J elfs, A. (2007). Face-to-face versus online tutoring support in distance education. Studies in Higher Education, 32(1) 1-20.

Quality Assurance Agency (2001). Guidelines for HE progress files. Retrieved from http:// www.qaa.ac.uk/ academicinfrastructure/ progressFiles/ default.asp

Quinn, F.M. (2005). Reflection and reflective practice. In C. Davies, L. Finlay, \&A. Bullman (Eds), Changing practice in health and social care ( $2^{\text {nd }}$ ed). London: Sage.

Ross, J . (2011). Unmasking online reflective practices in higher education (PhD Thesis). University of Edinburgh.

Ruch, G. (2000). Self and social work: Towards an integrated model of learning. J ournal of Social Work Practice, 14(2), 99-112.

Ruch, G. (2002). From triangle to spiral: Reflective practice in social work education, practice and research. Social Work Education, 21(2), 199-216.

Säljö, R. (1979). Learning in the learner's perspective. Reports from The Institute of Education, Gothenburg. University of Gothenburg.

Salmon, P. (1989). Personal stances in learning. In S. W. Weil \& I. J . McGill (Eds), Making sense of experiential learning. Buckingham: Open University Press/SRHE.

Schön, D. (1983). The reflective practitioner. San Francisco : J ossey-Bass. 
Schön, D. (1987). Educating the reflective practitioner. San Francisco: J ossey-Bass.

Stein, S., Shephard, K., \& Harris, I. (2011). Conceptions of e-learning and professional development for e-learning held by tertiary educators in New Zealand. British J ournal of Educational Technology, 42(1), 145-165.

Tisdell, E. J ., Strohschen, G. I. E., Carver, M. L., Corrigan, P., Nash, J ., Nelson, M., Royer, M., Strom-Mackey, R., \& O’Connor, M. (2004). Cohort learning online in graduate higher education : Constructing knowledge in cyber community. Educational Technology \& Society, 7(1), 115-127.

Trigwell, K., Prosser, M., \&Waterhouse, F. (1999). Relations between teachers' approaches to teaching and students' approaches to learning. Higher Education, 37, 57-70.

Van Manen, M. (1977). Linking ways of knowing with ways of being practical. Curriculum Inquiry, 6, 205-228.

Van Rossum, E., \& Hamer, R. (2010). The meaning of learning and knowing. Rotterdam: Sense Publishers.

Watts, A. G., \& Butcher, V. (2008). Break-out or break-up? Implications of institutional employability strategies for the role and structure of university careers services. Cambridge: National Institute for Careers, Education and Counselling (NICEC).

Wellington, B., \&Austin, P (1996). Orientations to reflective practice. Education Research, 38(3), 307-316. 


\section{Appendix A}

\section{Questionnaire}

\section{Demographic questions:}

1. How long have you worked as a distance tutor for the Open University?

2. How many presentations of B121 have you taught?

\section{Open-ended questions:}

3. When you think of e-Learning, what comes to mind?

4. When you think of teaching that includes e-Learning, what comes to mind?

5. What is your understanding of the purpose of the Tutor Group Forum (TGF)?

6. How do you use the TGF in teaching B121?

7. In what ways do you use the TGF to facilitate reflective learning for this course?

8. In what ways do you use the TGF to promote personal development among B121 learners?

9. How do your students use the TGF to engage in reflection and/ or personal development?

10. Please describe at least one example of how your students have (or haven't) responded to your efforts on the TGF.

11. How have you learned how to use the TGF as a teaching tool?

12. To what extent is your own teaching and/ or personal development supported as a distance tutor?

13. Please provide any questions thoughts about your own teaching or teachertraining that would be relevant to this project.

14. What do you mean by 'reflection'?

15. What do you mean by 'personal development'?

16. If you are willing to participate in a follow-up telephone interview, please provide your best telephone number(s) here. The date/ time will be arranged with you via email. 


\section{Appendix B}

\section{Interview Protocol}

1. As a distance tutor, how would you position yourself on a spectrum of novice to expert?

2. How important is the TGF in your role as a distance tutor?

3. To what extent do you feel it's important to prompt reflection in the forum?

4. What about personal development?

5. What has been problematic with your efforts to use the TGF in your teaching?

6. What has worked well on your forums?

7. To what extent do your students use the forum to reflect?

8. What evidence is there that learners have engaged with the forum for personal development?

9. Do you feel you would benefit from additional training in using the TGFs for distance learning?

10. What could the University or course team do to make the TGF a more effective teaching tool for you?

11. How could PDP be encouraged on the forum?

12. To what extent are you a reflective practitioner?

\section{Athabasca University $\mathbf{a}$}

(9) (1) 